\title{
Dank für 5 Jahre vorbildlichen Einsatz
}

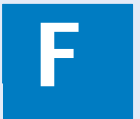

achlich kompetente, sachlich gut begründbare, aktuelle Fortbildung war Frau Prof. Kappstein immer ein besonderes Anliegen. Deshalb fiel bei ihr vor 5 Jahren der Wunsch des Thieme-Verlags, in der Schriftenreihe „up2date“ auch die Krankenhaushygiene anzubieten, auf fruchtbaren Boden. Unterstützt von zunächst zwei, später drei Mitstreitern war sie es, die bereit war, die Verantwortung zu übernehmen, die Herausforderungen des Anfangs mit all den unvermeidbaren Schwierigkeiten zu meistern, weil sie wusste, wie dringend nötig eine solche, auf die Belange der täglichen Praxis zugeschnittene Fortbildung ist.

Als Schriftleiterin, Koordinatorin und auch Autorin setzte sie sich über die Maßen ein und war insbesondere in der Anfangsphase der Garant der Zeitschrift. Ihre Stärke sind Praxiserfahrenheit und profunde Kenntnis nationaler wie internationaler Empfehlungen und Regelwerke. Ihr Markenzeichen ist, berechtigte Kritik klar und unnachgiebig vorzutragen. Die Evidenz einer Maßnahme, d.h. der Beweis einer Wirksamkeit aufgrund wissenschaftlich korrekt durchgeführter Studien mit dem Patienten als Bezugspunkt, galt ihr immer als das entscheidende Kriterium. Ihre außergewöhnliche Fähigkeit, Schwachpunkte von Publikationen wie Empfehlungen sofort zu erkennen, gepaart mit der Begabung, Sachverhalte in didaktisch klarer, für jeden Mitarbeiter verständlicher Form niederzuschreiben, hat sie in besonderer Weise für die Aufgabe der Schriftleitung einer Zeitschrift befähigt, die einem breit gefächerten Leserkreis über alle Berufsgruppen hinweg oftmals komplexe, manchmal mit Vorurteilen beladene Sachverhalte vermitteln will.

Wir Mitherausgeber bedauern die Entscheidung unserer Kollegin, ihr Amt als Herausgeberin niederzulegen, sehr. Wir wissen, dass die Lücke kaum zu schließen sein wird, aber wir schauen nach vorne und wollen wie bisher Qualität und Erfolg der Zeitschrift weiter vermehren.

Wir wünschen Ines Kappstein alles Gute, die Zeit, die sie sich wünscht und die Erfüllung, die sie sich daraus erhofft - und dass, wie sie es angedeutet hat, immer mal wieder so viel davon übrig bleibt, dass wir auch künftig in den Genuss ihrer kritischen Analysen von Empfehlungen und geübten Verhaltensmustern kommen werden - und mit uns die hoffentlich weiter wie bisher so zunehmende Zahl der Leser unserer Zeitschrift.

Mit ganz besonderem Dank und herzlichster Verbundenheit

Die Mitherausgeber 